\title{
Risk Factors for Necrotizing Enterocolitis: A Prospective Multicenter Case-Control Study
}

\author{
Daniel J.C. Berkhout ${ }^{a}$ b Patrick Klaassen ${ }^{b}$ Hendrik J. Niemarkt ${ }^{c}$ Willem P. de Boode ${ }^{d}$ \\ Veerle Cossey ${ }^{\mathrm{e}}$ Johannes B. van Goudoever ${ }^{\mathrm{f} g}$ Christiaan V. Hulzebos ${ }^{\mathrm{h}}$ Peter Andriessen ${ }^{\mathrm{c}}$ \\ Anton H. van Kaam ${ }^{i, j}$ Boris W. Kramerk Richard A. van Lingen' Daniel C. Vijlbriefm \\ Mirjam M. van Weissenbruch ${ }^{i}$ Marc Benninga ${ }^{a}$ Nanne K.H. de Boer ${ }^{n}$ Tim G.J. de Meij ${ }^{b}$ \\ ${ }^{a}$ Department of Pediatric Gastroenterology, Emma Children's Hospital / Academic Medical Center, Amsterdam, \\ The Netherlands; ${ }^{b}$ Department of Pediatric Gastroenterology, VU University Medical Center, Amsterdam,

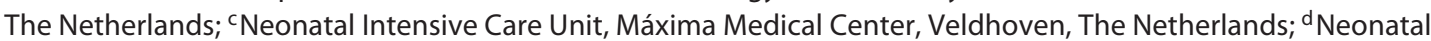 \\ Intensive Care Unit, Amalia Children's Hospital / Radboud University Medical Center, Nijmegen, The Netherlands; \\ eNeonatal Intensive Care Unit, University Hospitals Leuven, Leuven, Belgium; ${ }^{\mathrm{f}}$ Department of Pediatrics, Emma \\ Children's Hospital / Academic Medical Center, Amsterdam, The Netherlands; ${ }^{9}$ Department of Pediatrics, VU

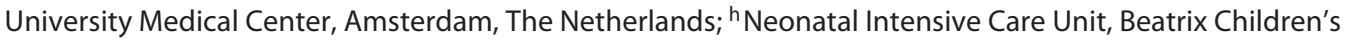 \\ Hospital / University Medical Center Groningen, Groningen, The Netherlands; 'Neonatal Intensive Care Unit, VU \\ University Medical Center, Amsterdam, The Netherlands; 'Neonatal Intensive Care Unit, Emma Children's Hospital / \\ Academic Medical Center, Amsterdam, The Netherlands; ${ }^{k}$ Department of Pediatrics, Maastricht University Medical \\ Center, Maastricht, The Netherlands; 'Neonatal Intensive Care Unit, Amalia Children's Center / Isala, Zwolle, \\ The Netherlands; ${ }^{m}$ Neonatal Intensive Care Unit, Wilhelmina Children's Hospital / University Medical Center Utrecht, \\ Utrecht, The Netherlands; ' Department of Gastroenterology and Hepatology, VU University Medical Center, \\ Amsterdam, The Netherlands
}

\section{Keywords}

Neonatology · Sepsis · Formula feeding $\cdot$ Risk factors · Mortality $\cdot$ Antibiotics

\begin{abstract}
Background: The identification of independent clinical risk factors for necrotizing enterocolitis (NEC) may contribute to early selection of infants at risk, allowing for the development of targeted strategies aimed at the prevention of NEC. Objective: The objective of this study was to identify independent risk factors contributing to the development of NEC in a large multicenter cohort. Methods: This prospective co-
\end{abstract}

\begin{tabular}{ll}
\hline KARGER & ( 2018 The Author(s) Karger \\
& Published by S. Karger AG, Basel Open access \\
E-Mail karger@karger.com & This article is licensed under the Creative Commons Attribution- \\
www.karger.com/neo & $\begin{array}{l}\text { NonCommercial-NoDerivatives 4.0 International License (CC BY- } \\
\text { NC-ND) (http://www.karger.com/Services/OpenAccessLicense). } \\
\text { Usage and distribution for commercial purposes as well as any dis- } \\
\text { tribution of modified material requires written permission. }\end{array}$
\end{tabular}

hort study was performed in 9 neonatal intensive care units. Infants born at a gestational age $\leq 30$ weeks were included. Demographic and clinical data were collected daily until day 28 postnatally. Factors predictive of the development of NEC were identified using univariate and multivariable analyses in a 1:5 matched case-control cohort. Results: In total, 843 infants (56 NEC cases) were included in this study. In the case-control cohort, univariate analysis identified sepsis prior to the onset of NEC and formula feeding to be associated

Dr. Berkhout and Dr. Klaassen contributed equally to this article and share co-first authorship.
Daniel J.C. Berkhout

Department of Pediatrics, VU University Medical Center De Boelelaan 1117

NL-1081 HV Amsterdam (The Netherlands)

E-Mail d.berkhout@vumc.nl 
with an increased risk of developing NEC, whereas the administration of antibiotics directly postpartum was inversely associated with NEC. In a multivariable logistic regression model, enteral feeding type and the number of days parenterally fed remained statistically significantly associated with NEC, whereas the administration of antibiotics directly after birth was associated with a lower risk of developing NEC. Conclusions: Formula feeding and prolonged (duration of) parenteral feeding were associated with an increased risk of NEC. Contrary to expectations, the initiation of treatment with antibiotics within $24 \mathrm{~h}$ after birth was inversely associated with NEC.

(C) 2018 The Author(s)

Published by S. Karger AG, Basel

\section{Introduction}

Necrotizing enterocolitis (NEC) is the most common severe gastrointestinal disease in infants born preterm. A new guideline on perinatal treatment of infants born extremely preterm was implemented in the Netherlands in 2010 , lowering the border of viability to support active treatment from 25 to 24 weeks' gestation. This resulted in an increase in NEC incidences (16\% in infants born at a gestational age $[\mathrm{GA}]<28$ weeks) and associated mortality [1].

The etiology of NEC is considered multifactorial, but the contribution of individual risk factors remains yet to be elucidated [2]. Several studies, mostly retrospective in design, have aimed to identify independent risk factors for NEC. Prematurity and low birth weight were the most consistently identified risk factors for the development of NEC [3]. Other reported risk factors include the administration of bovine-origin formula [4], low Apgar scores [5], small for GA [6], treatment of patent ductus arteriosus (PDA) [7], erythrocyte transfusions [8], and nosocomial infections [9]. Studies on potential effects of postnatal antibiotics on NEC incidence have shown conflicting results [10]. The identification of clinical factors contributing to the development of NEC may allow for the selection of neonates at risk for NEC and could contribute to the development of strategies aimed at the prevention and early treatment of NEC. Therefore, the aim of this study was to identify independent variables that are associated with the development of NEC. The daily collection of a wide variety of clinical variables, including exposure to antibiotics, allowed to explore their potential role in a detailed prospective manner.

\section{Patients and Methods}

\section{Patients}

This prospective cohort study, including infants born at a GA $\leq 30$ weeks, was conducted between October 2014 and January 2017 at 2 level III and 7 level IV neonatal intensive care units (NICUs) in the Netherlands and Belgium (online suppl. Table 1; for all online suppl. material, see www.karger.com/doi/10.1159/000489677). In that study, potential diagnostic biomarkers for NEC and sepsis are investigated $[11,12]$. None of the participating NICUs administered probiotics routinely. This study was approved by the local Institutional Review Boards of all 9 medical centers (2014.386 amendment A2016.363). Informed consent was obtained from all parents.

Data on GA, birth weight, gender, delivery mode, multiple births, preterm premature rupture of membranes (PPROM) ( $\geq 24 \mathrm{~h}$ before delivery), and Apgar scores were collected. Additional clinical data, including treatment of a significant PDA, diagnosis of NEC or sepsis, including causative organism, administration of antibiotics, transfusions with erythrocytes, use of central catheter, and parenteral and enteral feeding practices were prospectively collected. Data collection was ceased in case of transfer to another hospital. Infants were excluded in case of a missing or incomplete medical file.

\section{Definitions}

NEC cases were defined as infants diagnosed with NEC stage $\geq$ IIA (Bell's classification). NEC cases were independently reviewed by two experts (T.G.J.d.M. and H.J.N.), and consensus was met in all cases. Infants meeting all 3 Vermont Oxford criteria for sepsis were identified as sepsis cases, including (1) clinical symptoms of generalized infection (e.g., temperature instability, apnea, hemodynamic instability); (2) isolation of a pathogen from a blood culture; and (3) treatment with antibiotics for $\geq 5$ days directed to this pathogen [13]. A hemodynamically significant PDA was defined as an echocardiographic confirmed PDA for which pharmacological (ibuprofen, indomethacin) or surgical treatment was initiated.

Exposure to antibiotics was defined in two ways. The first definition, describing the duration of administrating antibiotics initiated within $24 \mathrm{~h}$ after birth, was categorized into (1) 0 days, (2) $\leq 3$ days, or (3) $>3$ days. In addition, types of antibiotics were also noted. The second definition described the cumulative number of days a patient was on any treatment with antibiotics. Exposure to central lines and red blood cell transfusion were noted as cumulative number of days any central line was present or erythrocytes were administered, respectively.

For enteral feeding types, we defined the following subgroups: (1) breast milk fed, defined as the average daily enteral feeding volume consisting of $\geq 80 \%$ breast milk, including donor milk; (2) formula fed, defined as the average daily enteral feeding volume consisting of $\geq 50 \%$ formula; and (3) a combination of both formula and breast milk, including infants not meeting the criteria of the first two subgroups. Full enteral feeding was defined when for at least two consecutive days no additional parenteral feeding (amino acids or lipids) was administered. Exposure to parenteral feeding was noted as the cumulative number of days any nutritional solution (lipids or amino acids) was administered parenterally. Increments in feeding volumes during the first 7 days postnatally were defined as the daily increase in enteral feeding volume relative to the birth weight $(\mathrm{mL} / \mathrm{kg} /$ day $)$. 
Table 1. Inclusions per participating center

\begin{tabular}{lllll}
\hline Center & $\begin{array}{l}\text { Inclusion period, } \\
\text { months }\end{array}$ & $\begin{array}{l}\text { Total inclusions, } \\
n(\%)\end{array}$ & $\begin{array}{l}\text { Incidence of NEC, } \\
n(\%)\end{array}$ & $\begin{array}{l}\text { Median age at the development of } \\
\text { NEC, days [IQR] }\end{array}$ \\
\hline 1 & 14 & $52(6.2)$ & $2(3.8)$ & 8.5 \\
2 & 28 & $179(21.2)$ & $8(4.5)$ & $14.5[6.5-19.8]$ \\
3 & 11 & $104(12.3)$ & $5(4.8)$ & $15[9-23.5]$ \\
4 & 17 & $90(10.7)$ & $5(5.6)$ & $16[13.5-22.5]$ \\
5 & 4 & $17(2.0)$ & $1(5.9)$ & 10 \\
6 & 27 & $114(13.5)$ & $8(7.0)$ & $14[7.5-22.3]$ \\
7 & 28 & $165(19.6)$ & $14(8.5)$ & $15[12-21.8]$ \\
8 & 27 & $65(7.7)$ & $6(9.2)$ & $9[6-10]$ \\
9 & 10 & $57(6.8)$ & $7(12.3)$ & \\
\hline
\end{tabular}

IQR, interquartile range; NEC, necrotizing enterocolitis.

\section{Statistical Analysis}

We performed two statistical analyses on the cohort. First, during the entire inclusion period of 28 days, demographic and clinical variables from all infants with NEC were compared with the variables from all infants without NEC. Second, each NEC case was matched to 5 controls, defined as infants without NEC. The matching procedure was based on GA (maximum difference of 3 days), birth weight (maximum difference of $400 \mathrm{~g}$ ), and postnatal age (total number of hospital days prior to NEC in matched cases). In this nested case-control cohort, variables of interest were collected for both the cases and matched controls from birth up to postnatal age of NEC diagnosis $\left(t_{0}\right)$. For example, if a case developed NEC on postnatal day 12, data was collected from both the case and matched controls from birth up to the postnatal age of 12 days.

Statistical analysis was performed with Statistical Package for the Social Science (SPSS) version 22.0. Predictive factors were identified by univariate analysis and corresponding $p$ values, odds ratios and 95\% confidence intervals were noted. Variables with a two-sided $p$ value $\leq 0.20$ were included in the multivariable logistic regression model. This model was constructed using the forward stepwise selection method, ultimately including statistically significant variables, defined as having a $p$ value $<0.05$. Since centerspecific incidence rates were relatively low, birth center was excluded from the regression models.

\section{Results}

\section{Total Cohort}

In total, 843 preterm infants were included during the study period. Fourteen (1.7\%) were excluded based on missing or incomplete medical files. Of the 829 remaining infants, 56 (6.8\%) developed NEC within the first 28 postnatal days. NEC was diagnosed at a median postnatal age of 12 days [IQR: 8.3-18 days]. The distribution of severity was stage IIA in 19 (33.9\%) cases, IIB in $16(28.6 \%)$ cases, IIIA in 8 (14.3\%) cases, and IIIB in 13 (23.2\%). Ta-

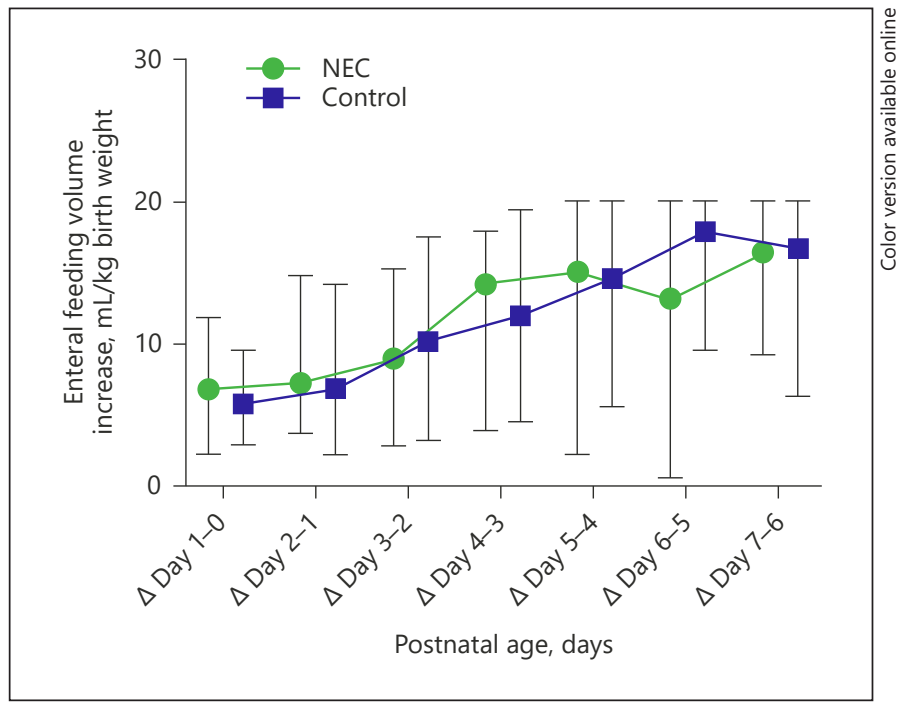

Fig. 1. Median daily enteral feeding volume increase during the first 7 postnatal days. Median daily enteral feeding volume increase $(\mathrm{mL} / \mathrm{kg} /$ day) with corresponding interquartile ranges are shown for both cases (dots) and controls (squares) within the 1:5 casecontrol cohort.

ble 1 depicts incidence rates per center (displayed encoded). An overview of the demographic and clinical characteristics of the cases versus controls during the entire inclusion period of 28 days is depicted in Table 2. In the NEC population, $21.4 \%$ of the infants died during the follow-up period, compared to $4.8 \%$ of the controls.

\section{Case-Control Cohort}

Overall, 56 cases and 280 matched controls were included in the case-control analysis. Outcomes of the uni- 
Table 2. Demographic and clinical characteristics of all included subjects per study group during the entire inclusion period of 28 days

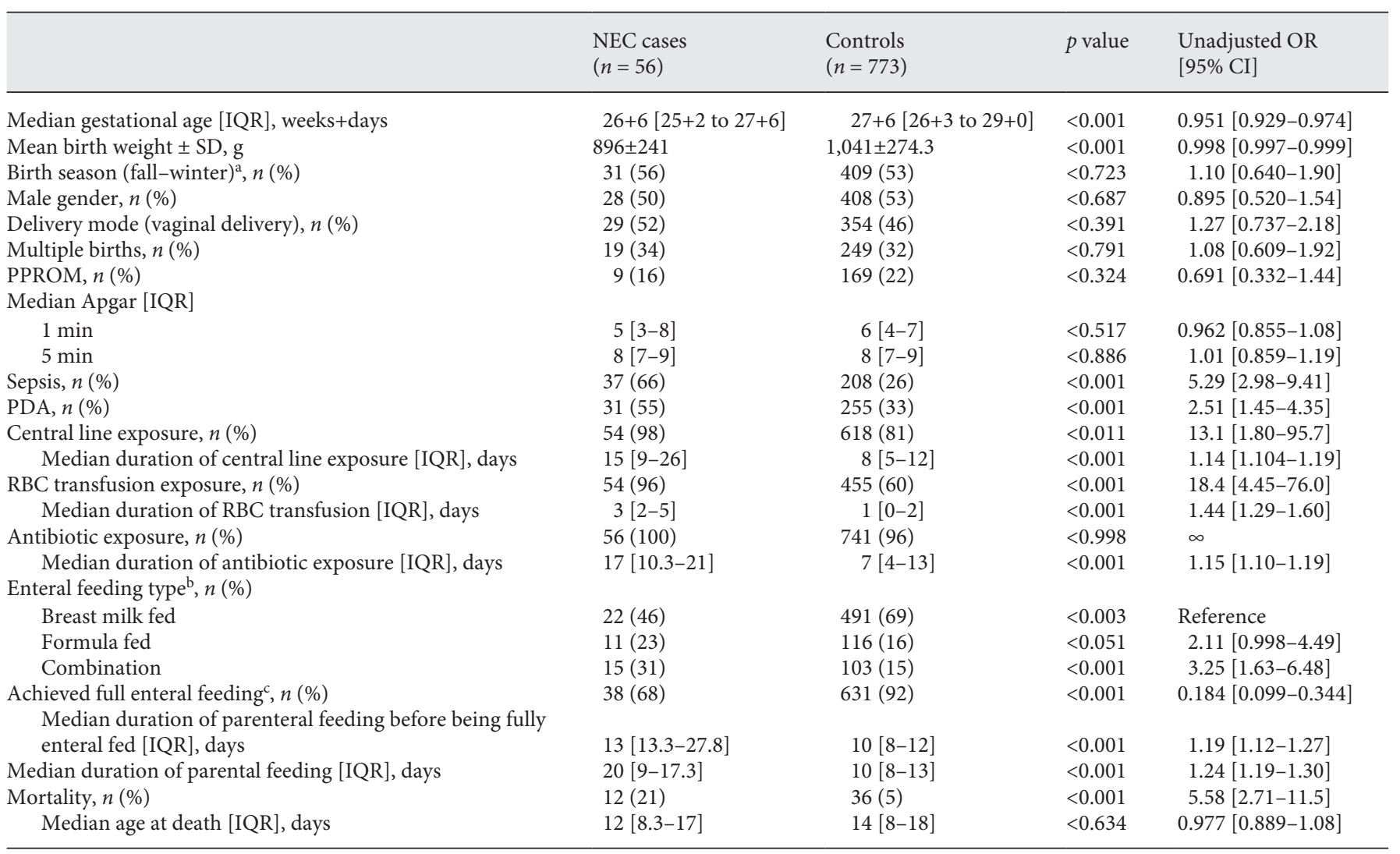

CI, confidence interval; IQR, interquartile range; OR, odds ratio; PPROM, preterm premature rupture of membranes; SD, standard deviation.

${ }^{\mathrm{a}}$ October up to March are defined as fall-winter ${ }^{\mathrm{b}}$ Variables were not retrievable from the medical records of one participating center $(n=71 \mathrm{missing}$ values). ${ }^{c}$ Variables were not retrievable from the medical records of one participating center ( $n=87$ missing values).

variate analysis are depicted in Table 3, demonstrating both sepsis and formula feeding prior to clinical presentation to be associated with an increased risk of developing NEC, whereas initiating of the administration of antibiotics within $24 \mathrm{~h}$ after birth was inversely associated with NEC. In total, $23.2 \%(n=13)$ of the cases did not receive antibiotics within $24 \mathrm{~h}$ after birth compared to $9.6 \%$ ( $n=$ 27) of the controls (Fig. 1a). Figure 1b depicts the types of antibiotics administered directly postnatally per study group. Daily enteral feeding increments per study group are depicted in Figure 2.

In the multivariable model, including all 8 variables with a $p$ value $\leq 0.20$ (online suppl. Table 2), treatment with antibiotics administrated directly postnatally $(p=$ 0.004 ) remained inversely associated with the development of NEC. More specifically, empiric use of antibiotics for a prolonged period of time ( $>3$ days) was associated with decreased odds of developing NEC (OR 0.227 [95\%
CI 0.079-0.648]; $p=0.006$ ), whereas the odds for infants receiving antibiotics for $\leq 3$ days maximally were: OR 0.213 [0.084-0.544]; $p=0.001$. Concerning formula feeding, the odds associated with the development of NEC increased for formula-fed infants (OR 3.36 [1.40-8.03]; $p=0.006)$ in the multivariable analysis compared to univariable analysis. In addition, the number of days infants received parenteral feeding prior to $\mathrm{t}_{0}$ (OR 1.19 [1.07$1.31] ; p=0.001)$ was also associated with an increased odds for developing NEC (Table 3).

\section{Discussion}

In this matched prospective multicenter cohort study, we aimed to identify demographic and clinical factors that preceded the development of NEC in preterm infants. Multivariable logistic regression modeling demon- 
Table 3. Characteristics of the NEC infants and the 5 matched controls per NEC case in the period preceding NEC diagnosis $\left(\mathrm{t}_{0}\right)$

\begin{tabular}{|c|c|c|c|c|c|c|}
\hline & $\begin{array}{l}\text { NEC } \\
(n=56)\end{array}$ & $\begin{array}{l}\text { Matched controls } \\
(n=280)\end{array}$ & $\begin{array}{l}p \\
\text { value }\end{array}$ & $\begin{array}{l}\text { Univariate analysis } \\
\text { OR }[95 \% \mathrm{CI}]\end{array}$ & $\begin{array}{l}p \\
\text { value }\end{array}$ & $\begin{array}{l}\text { Multivariable analysis } \\
\text { OR }[95 \% \mathrm{CI}]\end{array}$ \\
\hline Median gestational age [IQR], weeks+days & $26+6[25+3$ to $27+6]$ & $26+6[25+3$ to $27+6]$ & 0.936 & $1.00[0.974-1.03]$ & & \\
\hline Mean birth weight $\pm \mathrm{SD}, \mathrm{g}$ & $896 \pm 241$ & $892 \pm 314$ & 0.904 & $1.00[0.999-1.00]$ & & \\
\hline Birth season (fall-winter) ${ }^{\mathrm{a}}, n(\%)$ & $31(55)$ & $143(51)$ & 0.558 & $1.19[0.667-2.12]$ & & \\
\hline Male gender, $n(\%)$ & $28(50)$ & $139(50)$ & 0.961 & $1.01[0.571-1.80]$ & & \\
\hline Delivery mode (vaginal delivery), $n$ (\%) & $29(52)$ & $133(48)$ & 0.558 & $1.19[0.669-2.11]$ & & \\
\hline Multiple births, $n(\%)$ & $20(36)$ & $87(31)$ & 0.496 & $1.23[0.675-2.25]$ & & \\
\hline PPROM, $n(\%)$ & $9(16)$ & $66(24)$ & 0.217 & $0.618[0.288-1.33]$ & & \\
\hline \multicolumn{7}{|l|}{ Median Apgar [IQR] } \\
\hline $1 \mathrm{~min}$ & $5[3-8]$ & $5[3-7]$ & 0.403 & $1.06[0.929-1.20]$ & & \\
\hline $5 \mathrm{~min}$ & $8[7-9]$ & $7[6-8]$ & 0.186 & $1.13[0.943-1.35]$ & & \\
\hline Sepsis prior to $\mathrm{t}_{0}, n(\%)$ & $19(34)$ & $55(20)$ & 0.020 & $2.10[1.12-3.93]$ & & \\
\hline Gram negative & $3(16)$ & $14(26)$ & 0.549 & $0.549[0.139-2.17]$ & & \\
\hline Gram positive & $5(26)$ & $10(18)$ & 0.450 & $1.61[0.470-5.50]$ & & \\
\hline CoNS & $12(63)$ & $34(62)$ & 0.917 & $1.06[0.360-3.12]$ & & \\
\hline Fungi & $1(5)$ & $1(2)$ & 0.446 & $3.00[0.178-50.5]$ & & \\
\hline Sepsis within $24 \mathrm{~h}$ from $\mathrm{t}_{0}, n(\%)$ & $27(48)$ & $12(4)$ & $<0.001$ & $20.8[9.53-45.4]$ & & \\
\hline Gram negative & $15(56)$ & $4(33)$ & 0.206 & $2.50[0.604-10.3]$ & & \\
\hline Gram positive & $4(15)$ & $2(17)$ & 0.882 & $0.870[0.136-5.55]$ & & \\
\hline CoNs & $10(37)$ & $7(58)$ & 0.221 & $0.420[0.105-1.68]$ & & \\
\hline Fungi & 0 & 0 & n.a. & n.a. & & \\
\hline PDA, $n(\%)$ & $24(43)$ & $114(41)$ & 0.766 & $1.09[0.611-1.95]$ & & \\
\hline Ibuprofen last administered prior to t0 & $22(92)$ & $105(92)$ & 0.943 & $0.943[0.190-4.67]$ & & \\
\hline Time between last dose and $t_{0}[\mathrm{IQR}]$, days & $3.5[0-6.8]$ & $3[0-9]$ & 0.434 & $0.971[0.898-1.05]$ & & \\
\hline Central line exposure prior to $\mathrm{t}_{0}, n(\%)$ & $50(91)$ & $251(90)$ & 0.776 & $1.15[0.427-3.13]$ & & \\
\hline Median duration of central line exposure [IQR], days & $8.5[6-12]$ & $8[5-10.8]$ & 0.473 & $0.988[0.957-1.02]$ & & \\
\hline $\mathrm{RBC}$ transfusion exposure prior to $\mathrm{t}_{0}, n(\%)$ & $37(66)$ & $162(58)$ & 0.255 & $1.42[0.777-2.59]$ & & \\
\hline Median duration of RBC transfusion [IQR], days & $2[1-3]$ & $2[1-3]$ & 0.924 & $1.01[0.811-1.26]$ & & \\
\hline Time between last $\mathrm{RBC}$ transfusion and $\mathrm{t}_{0}[\mathrm{IQR}]$, days & $3[0.8-7]$ & $4[1-7]$ & 0.621 & $0.980[0.903-1.06]$ & & \\
\hline Infants with RBC transfusion within $48 \mathrm{~h}$ of $\mathrm{t}_{0}, n(\%)$ & $12(32)$ & $42(26)$ & 0.455 & $1.34[0.622-2.89]$ & & \\
\hline Antibiotic exposure prior to $\mathrm{t}_{0}, n(\%)$ & $51(91)$ & $269(96)$ & 0.119 & $0.417[0.139-1.25]$ & & \\
\hline Median antibiotic exposure [IQR], days & $6.5[3.3-10.8]$ & $6[3-9]$ & 0.407 & $1.03[0.966-1.09]$ & & \\
\hline Time between last administered antibiotics and $\mathrm{t}_{0}[\mathrm{IQR}]$, days & $3[0-6]$ & $2[0-6]$ & 0.536 & $0.981[0.924-1.04]$ & & \\
\hline \multicolumn{7}{|l|}{ Postpartum antibiotics, $n(\%)$} \\
\hline No antibiotics & $13(23)$ & $27(10)$ & 0.021 & Reference & 0.004 & Reference \\
\hline $1-3$ days of antibiotics & $28(50)$ & $170(61)$ & 0.007 & $0.342[0.158-0.741]$ & 0.001 & $0.213[0.084-0.544]$ \\
\hline$>3$ days of antibiotics & $15(27)$ & $83(30)$ & 0.026 & $0.375[0.159-0.887]$ & 0.006 & $0.227[0.079-0.648]$ \\
\hline \multicolumn{7}{|l|}{ Enteral feeding type, $n(\%)$} \\
\hline Breast milk fed & $27(56)$ & $169(65)$ & 0.110 & Reference & 0.015 & Reference \\
\hline Formula fed & $13(27)$ & $38(15)$ & 0.046 & $2.14[1.01-4.53]$ & 0.006 & $3.36[1.40-8.03]$ \\
\hline Combination & $8(17)$ & $18.9(20)$ & 0.895 & $0.945[0.405-2.20]$ & 0.824 & $0.902[0.364-2.23]$ \\
\hline $\begin{array}{l}\text { Mean enteral feeding volume increase during first } 7 \text { postnatal days } \pm \text { SD, } \\
\mathrm{mL} / \mathrm{kg} / \text { day }\end{array}$ & $10.1 \pm 5.1$ & $11.2 \pm 5.3$ & 0.162 & $0.962[0.911-1.02]$ & & \\
\hline Achieved full enteral feeding prior to $t_{0}, n(\%)$ & $30(54)$ & $106(41)$ & 0.094 & $1.64[0.919-2.94]$ & & \\
\hline Median time of parental feeding [IQR], days & $9[8-13]$ & $9[7-11]$ & 0.117 & $1.07[0.983-1.17]$ & 0.001 & $1.19[1.07-0.1 .31]$ \\
\hline Mortality, $n(\%)$ & $13(23)$ & $17(6)$ & $<0.001$ & $4.67[2.12-10.3]$ & & \\
\hline Median age at death [IQR], days & $12[8-7]$ & $16[9-17.5]$ & 0.315 & $0.930[0.808-1.07]$ & & \\
\hline
\end{tabular}

CI, confidence interval; IQR, interquartile range; OR, odds ratio; PPROM, preterm premature rupture of membranes; RBC, red blood cell; SD, standard deviation; $\mathrm{t}_{0}$, day of NEC onset.

${ }^{a}$ October up to March are defined as fall-winter.

strated only 2 independent variables to be associated with an increased risk of NEC: administration of predominantly formula feeding and the cumulative number of parental feeding days. Remarkably, administration of any antibiotics initiated within $24 \mathrm{~h}$ after birth was associated with a reduced risk of NEC.

NEC incidence in this cohort was $6.8 \%$. Although this reflects incidence rates described in larger international cohorts [14], it is considerably lower than that of a previous study in the Netherlands [1]. This apparent discrepancy may at least partly be explained by the limited follow-up period of 28 days. In the current study, $21.4 \%$ of the infants who developed NEC died prior to reaching the age of 28 days. Although this mortality rate is in line with available literature [15], NEC-associated mortality in this cohort may be higher due to the limited follow-up time of 28 days.
As expected, our study confirmed the significant role of low GA and birth weight as risk factors for the development of NEC. During the 28 days of follow-up, preterm infants with NEC were more exposed to antibiotics, central lines, and transfusions with erythrocytes, and they were less likely to reach full enteral feeding at the end of the inclusion period, reflecting the high morbidity rate of NEC.

An association between a hemodynamically significant PDA and NEC was demonstrated in the overall cohort but not in the case-control analysis. Presumably, the strong association between GA and PDA may be the explanation of this detected difference in the overall cohort, since the cases were born at a significantly lower GA. The currently observed absence of an association between transfusions with erythrocytes and NEC is supported by findings in a recent prospective observational study [16]. 

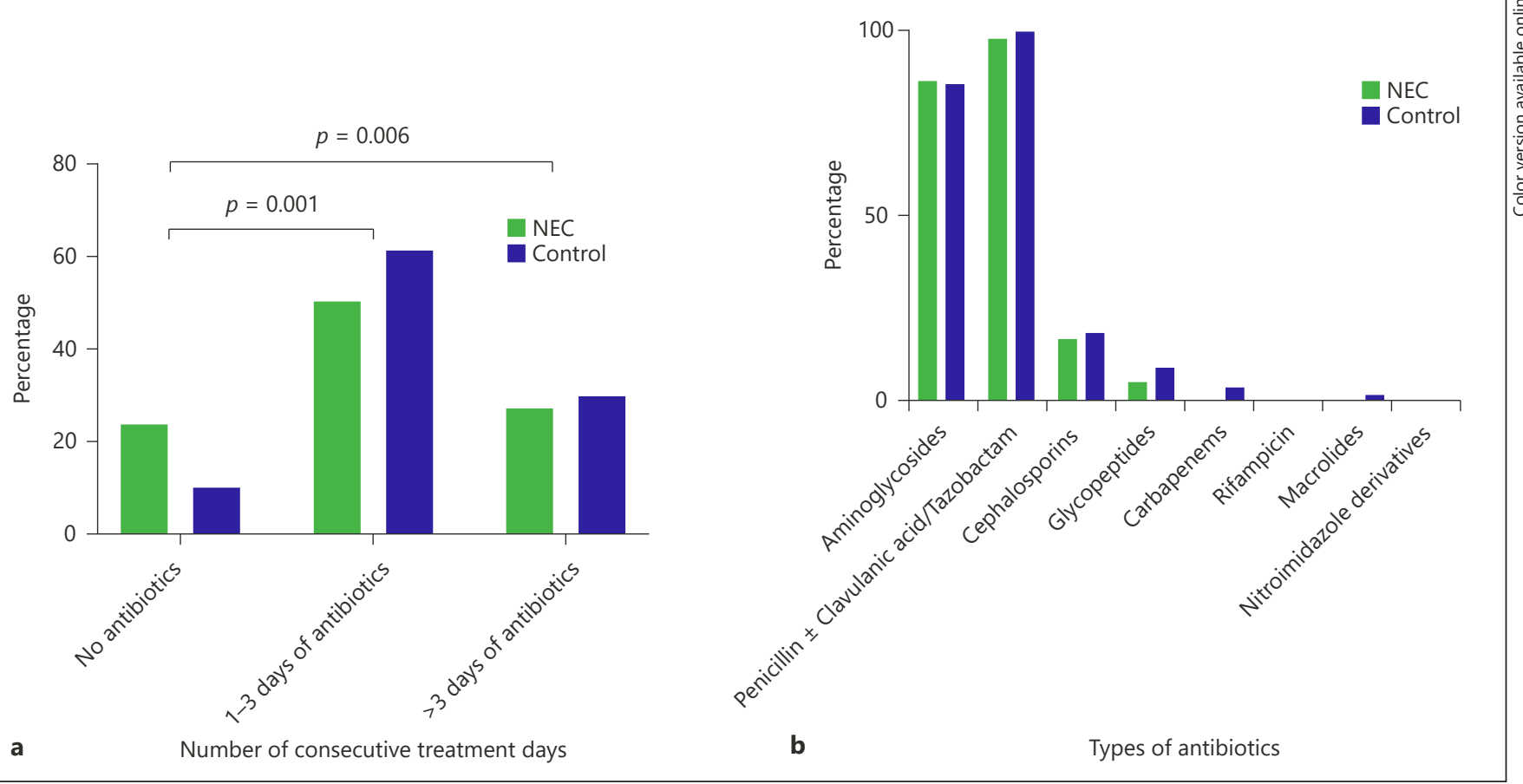

Fig. 2. Administration of antibiotics initiated within $24 \mathrm{~h}$ after birth in the matched case-control cohort. a Difference in number of consecutive days of treatment with any antibiotic. b Difference in types of administered antibiotics during the consecutive number of treatment days.

The initiation of antibiotics within $24 \mathrm{~h}$ after birth was inversely associated with the development of NEC. In contrast, Cotton et al. [17] demonstrated an increased risk of developing NEC with increasing treatment days. However, and in contrast to the current study, infants not exposed to antibiotics within $72 \mathrm{~h}$ postnatally were excluded. Our results are in line with the results of an observational single-center study describing a reversed association between early initiation of treatment with antibiotics (within $48 \mathrm{~h}$ after birth) and development of NEC [18]. In addition, a recent randomized controlled trial on preterm piglets demonstrated sustained administration of antibiotics initiated directly after birth to be protective against NEC [19]. Moreover, in a recent study by Heida et al. [20], a NEC-associated gut microbiota composition was already observed to be present in the meconium. These observations, in combination with the absence of any association between the development of NEC and the total number of days treated with antibiotics suggest that, in particular, initial intestinal colonization plays an essential role in the pathogenesis of NEC. Based on these findings, it could be hypothesized that microbial manipulation, for example through the administration of target- ed probiotics or antibiotics, may serve as an effective preventive strategy against NEC. Yet, the observational character of this study hampered the ability to explore any causal relationship between early colonization and the development of NEC. To prove any causality, future studies should focus on obstetrical and perinatal factors linked to longitudinal microbiota analysis.

In addition to these microbial factors, other potentially contributing factors need to be acknowledged. For example, it is tempting to speculate that pre-eclampsia or intra-uterine growth restriction might have caused suboptimal antenatal Doppler ultrasound features which in turn may have led to the decision to perform an emergency caesarean section. In these specific cases, administration of antibiotics is often not initiated since an intrauterine infection is not suspected. Therefore, merely the fetal Doppler ultrasound abnormalities [21] and not the absence of administration of antibiotics within $24 \mathrm{~h}$ after birth may have contributed to the increased association with the development of NEC.

In contrast to the univariate analysis, endurance of a septic episode in the entire period prior to NEC was not associated with an increased risk of developing NEC in 
the multivariable analysis. Interestingly, infants developing NEC had increased odds of developing sepsis within $24 \mathrm{~h}$ adjacent to clinical NEC diagnosis. Presumably, the release of pro-inflammatory cytokines and endotoxemia during NEC onset causes failure of the mucosal barrier function, ultimately leading to bacterial translocation and concurrent bloodstream infection [22].

In the literature, the concept of slow advancements in enteral feeding volumes and consequently an increased number of parenteral nutrition days demonstrated no significant alterations in the overall incidence of NEC except in infants with a birth weight $<750 \mathrm{~g}$ [23]. In contrast to the number of parenteral feeding days, the velocity of enteral feeding volume expansion during the first postnatal week was not associated with the development of NEC. Although enteral feeding advancements in the first week did not differ between the 2 groups, we hypothesize that enteral feeding intolerance present after the first postnatal week is more prevalent in infants developing NEC, explaining the observed increase in the cumulative number of parenteral feeding days.

In addition, the administration of predominantly formula feeding was associated with an increased risk of developing NEC. Both the presence of intact bovine proteins leading to intestinal inflammation [24] and the absence of human milk with associated protective properties [25] contribute to this increased risk. During this study, two centers started with supplementation of donor milk in cases where the production of the own mother's milk was insufficient. In the current study, we did not differentiate between donor milk and the own mother's milk. However, since supplementation with either donor milk or formula yielded similar short-term outcomes such as NEC [26], we hypothesize that the observed protective effect of the own mother's milk may potentially be higher than observed.

A strength of the current study is the prospective design with detailed daily data collection at 9 centers allowing us to match each case with 5 controls. By not including center of birth in the matching procedure, inter-center differences in medical policies (e.g., regarding feeding practices or types of antibiotics), potentially causing an increased risk of developing NEC, would possibly have been identified in the current study. This study also has several limitations. Firstly, to allow for adequate comparisons in the case-control cohort, control infants were matched based on their postnatal age. Consequently, all control infants at least survived their matched case and, therefore, may not have been an adequate representation of the overall population. Secondly, since the follow-up period was limited, infants developing NEC after this fol-

Identifying Risk Factors for Necrotizing Enterocolitis low-up period may hypothetically have been allocated to the control group. However, information concerning the development of NEC was collected for the entire NICU admission period. None of the selected controls were transferred before the corrected postmenstrual age (PMA) of 32 weeks. Since the majority of NEC cases occur before PMA of 30 weeks, the risk that a control infant developed NEC after PMA of 32 weeks and, thus, was incorrectly allocated to the control group is relatively low [14]. Thirdly, the current study is limited by the absence of detailed obstetric data, such as prenatal exposure to corticosteroids, pre-eclampsia, antenatal Doppler ultrasound features, chorioamnionitis, and intrapartum signs of infection. However, by including retrospectively collected variables to data which have been collected in a prospective manner would potentially result in biased outcomes and conclusions. Future studies should focus on the collection of both clinical and obstetric data while simultaneously performing longitudinal microbiota analyses to explore any causality between early administered antibiotics and the development of NEC. Furthermore, this study dealt with missing enteral and parenteral feeding practice values in approximately $10 \%$ of all included cases. Since all these cases originated from 2 centers, these values were not missing randomly and could, thus, not be statistically corrected for. Lastly, although the detailed manner of data collection allowed for the inclusion of a substantial number of different clinical variables, this also resulted in an increased risk of falsepositive discoveries (type I error) due to multiple testing.

Future studies should focus on validating the current study results by using an external cohort. Based on these findings, a prediction model may be constructed, allowing for the early identification and selection of those infants at risk of developing NEC. Subsequently, interventional studies may be performed to explore causality between the development of NEC and the currently identified clinical variables associated with NEC.

In conclusion, in this multicenter prospective cohort study multiple independent risk factors associated with the development of NEC were identified: predominate formula feeding and the cumulative number of parenteral feeding days. This is the first prospective multicenter study describing that exposure to antibiotics initiated within $24 \mathrm{~h}$ after birth is associated with a decreased risk of developing NEC. This observation seems to underline the increasing notion that early intestinal colonization might play a pivotal role in the pathogenesis of NEC and opens avenues towards the development of microbiota-based preventive strategies in order to reduce NEC incidences. 


\section{Acknowledgements}

We would like to thank Dr. Lissenberg-Witte for her excellent help with the analysis and her assistance during the interpretation of the results.

\section{Statement of Ethics}

This study was approved by the local Institutional Review Boards of all 9 medical centers (2014.386 amendment A2016.363). Informed consent was obtained from all parents.

\section{Disclosure Statement}

The authors declare no conflicts of interest.

\section{References}

1 Heida FH, Stolwijk L, Loos MH, van den Ende SJ, Onland W, van den Dungen FA, Kooi EM, Bos AF, Hulscher JB, Bakx R: Increased incidence of necrotizing enterocolitis in the Netherlands after implementation of the new Dutch guideline for active treatment in extremely preterm infants: results from three academic referral centers. J Pediatr Surg 2017; $52: 273-276$

2 Niemarkt HJ, de Meij TG, van de Velde ME, van der Schee MP, van Goudoever JB, Kramer BW, Andriessen P, de Boer NK: Necrotizing enterocolitis: a clinical review on diagnostic biomarkers and the role of the intestinal microbiota. Inflamm Bowel Dis 2015;21:436-444.

3 Samuels N, van de Graaf RA, de Jonge RCJ, Reiss IKM, Vermeulen MJ: Risk factors for necrotizing enterocolitis in neonates: a systematic review of prognostic studies. BMC Pediatr 2017;17:105.

4 Battersby C, Longford N, Mandalia S, Costeloe K, Modi N; UK Neonatal Collaborative Necrotising Enterocolitis (UKNC-NEC) study group: Incidence and enteral feed antecedents of severe neonatal necrotising enterocolitis across neonatal networks in England, 2012-13: a whole-population surveillance study. Lancet Gastroenterol Hepatol 2017;2:43-51.

5 Seeman SM, Mehal JM, Haberling DL, Holman RC, Stoll BJ: Infant and maternal risk factors related to necrotising enterocolitis-associated infant death in the United States. Acta Paediatr 2016;105:e240-246.

6 Ree IM, Smits-Wintjens VE, Rijntjes-Jacobs EG, Pelsma IC, Steggerda SJ, Walther FJ, Lopriore E: Necrotizing enterocolitis in small-for-gestational-age neonates: a matched case-control study. Neonatology 2014;105:74-78.

7 El-Mashad AE, El-Mahdy H, El Amrousy D, Elgendy M: Comparative study of the efficacy and safety of paracetamol, ibuprofen, and indomethacin in closure of patent ductus arteriosus in preterm neonates. Eur J Pediatr 2017;176:233-240.

8 Mohamed A, Shah PS: Transfusion associated necrotizing enterocolitis: a meta-analysis of observational data. Pediatrics 2012;129:529-540.

9 Zvizdic Z, Heljic S, Firdus A, Jonuzi A, Zvizdic D: Relationship of nosocomial infections with the development of necrotizing enterocolitis in preterm infants. Mater Sociomed 2014;26:4-6.

10 Esaiassen E, Fjalstad JW, Juvet LK, van den Anker JN, Klingenberg C: Antibiotic exposure in neonates and early adverse outcomes: a systematic review and meta-analysis. J Antimicrob Chemother 2017;72:1858-1870.

11 Berkhout DJ, Niemarkt HJ, Buijck M, van Weissenbruch MM, Brinkman P, Benninga MA, van Kaam AH, Kramer BW, Andriessen P, de Boer NK, de Meij TG: Detection of sepsis in preterm infants by fecal volatile organic compounds analysis: a proof of principle study. J Pediatr Gastroenterol Nutr 2017; 65:e47-e52.

12 de Meij TG, van der Schee MP, Berkhout DJ, van de Velde ME, Jansen AE, Kramer BW, van Weissenbruch MM, van Kaam AH, Andriessen P, van Goudoever JB, Niemarkt HJ, de Boer NK: Early detection of necrotizing enterocolitis by fecal volatile organic compounds analysis. J Pediatr 2015;167:562-567 e561.

13 Vermont Oxford Network: 2016. Manual of Operations: Part 2. Data Definitions \& Infant Data Forms. Burlington, Vermont Oxford Network, 2015.

14 Yee WH, Soraisham AS, Shah VS, Aziz K, Yoon W, Lee SK; Canadian Neonatal Network: Incidence and timing of presentation of necrotizing enterocolitis in preterm infants. Pediatrics 2012;129:e298-e304.

15 Berman L, Moss RL: Necrotizing enterocolitis: an update. Semin Fetal Neonatal Med 2011;16:145-150.

16 Patel RM, Knezevic A, Shenvi N, Hinkes M Keene S, Roback JD, Easley KA, Josephson CD: Association of red blood cell transfusion, anemia, and necrotizing enterocolitis in very lowbirth-weight infants. JAMA 2016;315:889-897.

17 Cotten CM, Taylor S, Stoll B, Goldberg RN, Hansen NI, Sanchez PJ, Ambalavanan N, Benjamin DK Jr; NICHD Neonatal Research Network: Prolonged duration of initial empirical antibiotic treatment is associated with increased rates of necrotizing enterocolitis and death for extremely low birth weight infants. Pediatrics 2009;123:58-66.

18 Krediet TG, van Lelyveld N, Vijlbrief DC, Brouwers HA, Kramer WL, Fleer A, Gerards
LJ: Microbiological factors associated with neonatal necrotizing enterocolitis: protective effect of early antibiotic treatment. Acta Paediatr 2003;92:1180-1182.

19 Jensen ML, Thymann T, Cilieborg MS, Lykke M, Molbak L, Jensen BB, Schmidt M, Kelly D, Mulder I, Burrin DG, Sangild PT: Antibiotics modulate intestinal immunity and prevent necrotizing enterocolitis in preterm neonatal piglets. Am J Physiol Gastrointest Liver Physiol 2014;306:G59-G71.

20 Heida FH, van Zoonen A, Hulscher JBF, Te Kiefte BJC, Wessels R, Kooi EMW, Bos AF, Harmsen HJM, de Goffau MC: A necrotizing enterocolitis-associated gut microbiota is present in the meconium: results of a prospective study. Clin Infect Dis 2016;62:863-870.

21 Westby Eger S, Kessler J, Kiserud T, Markestad T, Sommerfelt K: Foetal Doppler abnormality is associated with increased risk of sepsis and necrotising enterocolitis in preterm infants. Acta Paediatrica 2015;104:368-376.

22 Sharma R, Tepas JJ 3rd, Hudak ML, Mollitt DL, Wludyka PS, Teng RJ, Premachandra BR: Neonatal gut barrier and multiple organ failure: role of endotoxin and proinflammatory cytokines in sepsis and necrotizing enterocolitis. J Pediatr Surg 2007;42:454-461.

23 Viswanathan S, McNelis K, Super D, Einstadter D, Groh-Wargo S, Collin M: Standardized slow enteral feeding protocol and the incidence of necrotizing enterocolitis in extremely low birth weight infants. JPEN J Parenter Enteral Nutr 2015;39:644-654.

24 Di Lorenzo M, Bass J, Krantis A: An intraluminal model of necrotizing enterocolitis in the developing neonatal piglet. J Pediatr Surg 1995;30:1138-1142.

25 Maffei D, Schanler RJ: Human milk is the feeding strategy to prevent necrotizing enterocolitis! Semin Perinatol 2017;41:36-40.

26 Corpeleijn WE, de Waard M, Christmann V, van Goudoever JB, Jansen-van der Weide MC, Kooi EM, Koper JF, Kouwenhoven SM, Lafeber HN, Mank E, van Toledo L, Vermeulen MJ, van Vliet I, van Zoeren-Grobben D: Effect of donor milk on severe infections and mortality in very low-birth-weight infants: the Early Nutrition Study Randomized Clinical Trial. JAMA Pediatr 2016;170:654-661. 